\title{
The Phenomenology of Kantian Respect for Persons
}

\author{
Uriah Kriegel \& Mark Timmons ${ }^{1}$
}

Forthcoming in Respect, R. Dean \& O. Sensen, eds., Cambridge UP

\begin{abstract}
Emotions can be understood generally from two different perspectives: (i) a third-person perspective that specifies their distinctive functional role within our overall cognitive economy and (ii) a first-person perspective that attempts to capture their distinctive phenomenal character, the subjective quality of experiencing them. One emotion that is of central importance in many ethical systems is respect (in the sense of respect for persons or so-called recognition-respect). However, discussions of respect in analytic moral philosophy have tended to focus almost entirely on its functional role, in particular the behaviors that respect disposes us to engage in (or refrain from). Here we wish to investigate the phenomenal character of respect, what it is like to feel respect for persons. Since Kant is the reference point for modern discussions of respect, we try to reconstruct Kant's account of the phenomenology of respect, but also endeavor to refine his account in light of our own phenomenological observations.
\end{abstract}

\section{Respect and Moral Phenomenology}

In the opening chapter of his book The Conscious Mind, David Chalmers (1996) argues that many mental terms lead a "double life": they have a psychological life and a phenomenological life. To say that a term $\mathrm{T}$ leads a double life is to say that $\mathrm{T}$ tokens tend to cluster into two distinct types, each expressing a different concept. Thus, we use the word "pain" in two discernibly different ways, expressing two different concepts, which we may call the psychological concept of pain and a phenomenological concept of pain. These concepts may or may not pick out the same property, but however that turns out, they are distinct concepts. ${ }^{2}$

\footnotetext{
${ }^{1}$ This chapter is thoroughly collaborative; the order of authorship is alphabetical. Work for it was supported by the French National Research Agency's grants ANR-11-0001-02 PSL* and ANR-10LABX-0087. A version of this paper was delivered at the June 2020 meeting of the North American Kant Society. We are grateful to the audience there, in particular Lucy Allais.

${ }^{2}$ Chalmers himself thinks they turn out to also pick out different properties, but this does not fall out of the thesis of the double life of mental terms. The argument for it arrives rather later in the book (mostly Ch. 2). The purview of the double-life thesis thus concerns, in the first place, only the realm of concepts.
} 
What are these notions of "psychological concept" and "phenomenological concept"? According to Chalmers, mental phenomena can be conceived either in terms of their functional role within the subject's psychological economy, or in terms of their phenomenal character, what it is like for their subject to undergo them. The psychological conception of mind characterizes mental phenomena thirdpersonally in terms of their causal relations to each other and to the environment; the phenomenological conception characterizes them first-personally in terms of their phenomenal or subjective feel. Thus the former focuses on the mechanical dimension of mental life, the latter on its experiential dimension. Most mental terms, suggests Chalmers, can be understood either as expressing a third-person, functional-role conception of the relevant mental phenomenon or as expressing a first-person, phenomenal-character conception of it. Thus, mental states can be classified as pains either because (roughly) they are caused by harmful stimulation and cause aversive reaction or because they feel that particular unpleasant way they hurt. Correspondingly, the term "pain" can be used to express either (i) the concept of a mental state caused by harmful stimulation and causing aversive reaction or (ii) the concept of a mental state that feels that unpleasant way. The former is the psychological concept of pain, the latter the phenomenological concept of pain. ${ }^{3}$

The double-life thesis seems particularly compelling for the emotions. Fear tends to be triggered by objects or events that appear dangerous and tends to provoke characteristic reactions of fight or flight; these causes and effects of fear are publicly observable and third-personally describable. But fear also feels a certain unmistakable way, a way it is much harder to describe in public language; when any token conscious fear occurs, only one person experiences the relevant instance of that feeling. Crucially, it is unclear how one could "read off" the phenomenal character of fear from a complete specification of fear's functional role. Likewise, anger tends to be triggered by wrongs, offenses, slights, etc. and to provoke a pull to rectification and/or revenge. But in addition, it involves a distinctive, unpleasantly

\footnotetext{
3 Unless we recognize this ambiguity of "pain," we are liable to fall into puzzle and paradox. Thus, when a toothached subject must suddenly attend to a fire in the kitchen and no longer feels her toothache, does it still qualify as pain? When she feels again the toothache after the fire has been put out, is she feeling the same pain as before or a new, numerically distinct pain? Such questions are readily answered once we distinguish between the psychological and the phenomenological concepts of pain. When we do, it becomes straightforward that unfelt pain qualifies as pain in the psychological sense but not in the phenomenological sense, and accordingly, our subject has the same pain throughout in the psychological sense but two different pains in the phenomenological sense. The underlying reason is that while the subject's toothache-related state during the fire preserves much of the functional role it had before the fire, it loses its phenomenal character entirely. (At least this is what the description of the case as involving unfelt pain suggests. One might of course contest this description, with different implications arising for what to say about such cases.)
} 
consuming subjective feeling or experience, which cannot in any obvious way be "read off of" its functional role. Thus fear and anger can be conceptualized in two systematically distinct ways: in terms of functional role or in terms of phenomenal character. That is, they can be conceptualized either psychologically or phenomenologically. Similar remarks apply in all likelihood to most other emotions. ${ }^{4}$

Among the emotions most central to ethical theory is respect. Of particular significance is the kind of respect highlighted by Kant - what is sometimes called "respect for persons as such." This is the respect we feel toward someone not because of her particular accomplishments or attributes, but simply because she is a person. It is the kind of respect we have toward $x$ when $x^{\prime}$ s being a person is sufficient ground for our respecting $x$.

If the double-life thesis is on the right track, such respect can be conceptualized in two different ways. On the one hand, it can be characterized thirdpersonally in terms of its distinctive functional role in our psychological economy, the kinds of causes and effects that tend to trigger it and tend to be provoked by it. To seek the right such characterization is to engage in the moral psychology of respect for persons. On the other hand, this kind of respect can also be characterized first-personally in terms of its distinctive phenomenal character, the subjective experience of occurrently feeling respect for a person. To seek the right firstpersonal characterization of respect's phenomenal character is to engage in the moral phenomenology of respect for persons.

In describing the kind of respect we are interested in as an emotion - that is, as an experiential episode the subject feels on particular occasions as part of her stream of consciousness - we do not intend to deny that it can also occur in our mental life as an attitude, that is, as a tacit or latent state that characterizes the

\footnotetext{
${ }^{4}$ There are in fact three features traditionally thought to make up the core of mental life: functional role, phenomenal character, and intentional content. The psychological conception of mind focuses on the first, the phenomenological conception on the second. What about the third? Is there also an intentional conception of mind? Such a conception could very likely be formulated, but in the present context it would be more profitable to note that the notion of intentionality itself splits in two. On the one hand, we have the notion of intentionality as based on functional role, perhaps long-armed role that includes connections to the environment and actions (Harman 1987). On the other hand, there is also the notion of intentionality as based on satisfaction conditions constituted by phenomenal character (Horgan and Tienson 2002, Loar 2003). In light of this, we might just distinguish two kinds of intentionality - psychological intentionality and phenomenal intentionality - and to build the former into the psychological conception of mind and the latter into the phenomenological conception (Kriegel 2010).
} 
subject's standing stance toward the world. On the contrary, we countenance both a respect-emotion and a respect-attitude. ${ }^{5}$ However, we focus here on the emotion rather than the attitude because, arguably, phenomenal character is more essential to an emotion's nature, whereas what is more essential to an attitude's nature is its functional role. And what we want to pursue here is the moral phenomenology of respect.

In analytic moral philosophy, by far the most contributions to our understanding of respect for persons have come from moral psychology, not moral phenomenology. Thus, in his seminal "Two Kinds of Respect," Stephen Darwall (1977) isolates a kind of respect he calls "recognition-respect," which he distinguishes from "appraisal-respect" and characterizes as follows:

There is a kind of respect which ... consists, most generally, in a disposition to weigh appropriately in one's deliberations some feature of the thing in question and to act accordingly... To say that persons as such are entitled to respect [of this kind] is to say that they are entitled to have other persons take seriously and weigh appropriately the fact that they are persons in deliberating about what to do. Such respect is recognition respect... (Darwall 1977: 38)

It is clear that what Darwall has in mind with his notion of recognition-respect is what we have called above respect for persons - or at least that respect for persons is a special case of recognition-respect (namely, the case where the fact recognized is that someone is a person). But it is also clear that what Darwall has in mind is a phenomenon characterized in terms of functional role. This becomes evident when Darwall offers his fuller account of recognition-respect:

Some fact or feature is an appropriate object of [recognition] respect if inappropriate consideration or weighing of that fact or feature would result in behavior that is morally wrong. To respect something is thus to regard it as requiring restrictions on the moral acceptability of actions connected with it... To have such respect for the law, say, is to be disposed to regard the fact that something is the law as restricting the class of actions that would be morally permissible. (Darwall 1977: 43)

This account of recognition-respect clearly proceeds by trying to correctly identify an attitude with a distinctive functional role. ${ }^{6}$ Respect for persons is said to be that

\footnotetext{
${ }^{5}$ We also acknowledge there are complicated questions surrounding their relationship. On one end of the spectrum is the view that the attitude is the psychologically substantive state here, with the emotion being a sort of occasional epiphenomenal spurt. On the other end of the spectrum, there is the view that the attitude is nothing but the disposition to undergo the emotional experience, so that we really have no handle on the attitude independent of our handle on the emotion. And there is any number of in-between options. We bracket those issues here.

${ }^{6}$ Moreover, the attitude in question is, for Darwall, precisely the attitude Kant had in mind in discussing respect: "it is to recognition respect of persons that Kant refers when he writes, 'Such a being is therefore an object of respect and, so far, restricts all (arbitrary) choice'" (Darwall 1977: 45).
} 
mental state which is triggered by persons (or objects appearing to one to be persons) and which provokes a narrowing-down of the potential courses of action toward those objects (and does so in light of these objects appearing to be persons).

Other treatments of respect in the extant literature follow a very similar pattern, disagreeing mostly on the correct analysis of respect's functional role. We do not wish to call into question the insight into the nature of respect afforded by such analyses. We suspect, however, that there is an additional and complementary kind of insight into the nature of respect that could be had, one obtained by articulating the phenomenal character of respect - what it is like for us to occurrently experience respect for someone solely on account of her being a person. We suspect, moreover, that here too, the subjective quality of respect cannot be "read off" from any specification of respect's functional role, however exhaustive. A full portrait of respect for persons would thus comprise both a psychological chapter and phenomenological chapter, tracing out both the functional role and the phenomenal character characteristic of respect as an attitude and as an emotion. Since the literature has tended to focus on the moral psychology of respect, here we focus on the moral phenomenology of respect.

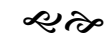

The literature's focus on functional role is not accidental. There is a sustained worry that first-person inquiry into phenomenal feel is bound to run into principled difficulties. Thus, the deliverances of introspection of our lived experience are often thought to be untrustworthy. In addition, it is unclear how we might put into words those deliverances, whatever their epistemic status. It is a familiar refrain in discussions of conscious experience, after all, that phenomenal character is ultimately ineffable, or perhaps more accurately incommunicable: it can be named, but it cannot be described. No informative account of the phenomenal character of seeing yellow can be offered to the colorblind, arguably. By the same token, one might claim, no informative account of what it is like to feel respect could be offered to someone constitutionally incapable of feeling it. If so, it is unclear how moral phenomenology could contribute anything substantial to our understanding of respect.

We have addressed elsewhere some of these foundational issues stalking moral phenomenology and indeed phenomenology writ large (Horgan and Timmons 2005, 2008, Kriegel 2008, 2015 inter alia). Heeding the precept that the proof is in the pudding, however, here we would like to consider what kind of phenomenological pudding could be made of respect for persons! We propose to 
simply go ahead with the project of characterizing the phenomenal character of such respect, with the hope that the very possibility of intelligible discussion of the topic would constitute a retroactive partial demonstration of the project's viability. Before starting, however, some general remarks might prove useful.

In mathematics, an axiomatic system's primitives are officially taken to be incommunicable. Nonetheless, they are thought to be understood informally in terms of their theoretical role within the relevant system. Thus, notions appearing in the theorems of a given axiomatization of Euclidean Geometry are defined in terms of notions appearing in the system's axioms; but the notions appearing in the axioms are understood only in terms of their role within these axioms (Hilbert 1900). Indeed, the axioms can be thought of as nothing more than descriptions of a web of interrelations among opaque nodes, with each node designated by a different conceptually primitive notion. Our grasp on the nature of these nodes is exhausted by the interrelations specified in these axioms. These theoretical roles can be articulated most straightforwardly using Ramsey sentences: sentences asserting the existence of something that satisfies a vast collection of descriptors (Lewis 1966, 1972).

This approach could be imported into moral phenomenology, with central phenomenological observations regarding some types of moral experience taking the role of the axioms in a mathematical system. Consider, if only for the sake of illustration, the following collection of broadly phenomenological observations about respect, harvested more or less verbatim from the Stanford Encyclopedia entry on respect (Dillon 2018):

- Respect is a particular mode of apprehending the object: the person who respects something pays attention to it and perceives it differently.

- Respect often feels like trying to see the object clearly, as it really is in its own right, and not seeing it solely through the filter of one's own desires and fears or likes and dislikes.

- Respect feels object-generated rather than wholly subject-generated, something that is owed to, called for, deserved, elicited, or claimed by the object.

- Respect feels deliberate, a matter of directed rather than grabbed attention, of reflective consideration and judgment.

- Respect involves "a deontic experience" - the experience that one must pay attention and respond appropriately.

- We respect something not because we want to but because we recognize that we have to respect it. 
- Respect is the recognition of something "as directly determining our will without reference to what is wanted by our inclinations" (Rawls 2000: 153).

- Respect feels reason-governed: it feels like we cannot respect a particular object for just any old reason or for no reason at all.

- Respect feels universalizing, in the sense that if $\mathrm{F}$ is a respect-warranting feature of object 0 , then respecting $\mathrm{O}$ on account of $\mathrm{F}$ commits us, other things equal, to respecting other things that also have feature $\mathrm{F}$.

A comprehensive moral phenomenology of respect would involve a great many observations of this sort, which could then be 'Ramsified' to capture the theoretical role of the experience of respect in the theory, thus providing the reader with a textured sense of respect's phenomenal character. ${ }^{7}$

This approach presupposes that there is sufficient uniformity among people's respect experiences, something that may well be called into question (Gill 2008, Sinnott-Armstrong 2008). Certainly there may be little uniformity at a very fine grain of determinacy. At the same time, one might hope that at a sufficient level of generality, certain recurring patterns might be found interpersonally, such that even if different subjects find it difficult to produce similar phenomenological descriptions of respect, when they consume phenomenological descriptions of respect, some descriptions simply resonate with - command assent from - many.

In keeping with our pudding gambit, here we will assume that there is sufficient uniformity in people's respect experiences to make it possible to produce descriptions of those experiences - descriptions which do, or would, command widespread assent. The challenge is how to characterize the common component of felt respect for persons in as substantive and informative a manner. Discussions of respect for persons in the extant literature often start out from Kant's remarkably influential account of it. Here too, though, philosophers have tended to focus on the functional role, rather than phenomenal character, Kant assigned to respect. We believe, however, that Kant's moral writings contain fundamentally accurate, if somewhat incomplete, characterizations of the phenomenal character of recognition-respect; characterizations that can be more fully developed and defended against various objections. In what follows, we propose to build on Kant's insight but in a more overtly phenomenological direction than is common in the extant literature. We propose, in other words, to develop a broadly Kantian phenomenology of recognition-respect for persons. This task will occupy us for the

\footnotetext{
${ }^{7}$ Note that although for Lewis specifying a theoretical role for a term was supposed to go hand in hand with offering a functionalist assay of the T's denotation, the two are separate moves. When $\mathrm{T}$ is a term appearing in a phenomenological theory, T's theoretical role is the role it plays in an overall phenomenological, hence non-functional, characterization of T's denotation.
} 
next two sections. In the final section, we will briefly consider some outstanding challenges, pointing the way for further research. ${ }^{8}$

\section{Kant on the Experience of Recognition-Respect: I. A Footnote in the Groundwork}

Kant's account of the phenomenology of recognition-respect is found primarily in his 1797 Doctrine of Virtue (part II of the Metaphysics of Morals), where he discusses duties of virtue toward others. ${ }^{9}$ However, already in the 1785 Groundwork the feeling of respect is described in some detail in a long footnote, where, having characterized duty as "the necessity of an action from respect for law" (G 4:400), Kant responds to a potential worry that reference to respect is merely "an obscure feeling" that has no place in a purely rationalist ethical theory (G 4:401n). It is worth quoting the footnote almost in full (leaving out the first sentence that raises the worry), and in two parts. Inserting bracketed numbers to separate individual claims Kant makes, the passage reads:

[T] hough [0] respect is a feeling, [1] it is not one received by means of influence; [2] it is instead a feeling self-wrought (selbstgewirktes) by means of a rational concept and [3] therefore specifically different from all feelings of the first kind, which can be reduced to inclination or fear. [4] What I cognize (erkenne) immediately as a law for me I cognize with respect, [5] which signifies merely consciousness of the subordination of my will to a law without the mediation of other influences on my sense. [6] Immediate determination of the will by means of the law and consciousness of this is called respect, [7] so that it is regarded as an effect of the law on the subject, [8] and not as the cause of the law.

Of these eight claims, only 4 and 5 clearly include phenomenological observations. ${ }^{10}$ However, they reveal what is at the heart of this feeling of respect, namely, consciousness of the subordination of one's will to the law, not mediated by one's antecedent desires or aversions. This consciousness of subordination, in its fullness, involves further elements:

\footnotetext{
${ }^{8}$ Note well: we do not wish to claim that Kant's only notion of respect is that of recognition-respect; on the contrary, we agree with Darwall (2008), that some of it concerns a kind of moral appraisal-respect. Thus, in the second Critique, Kant describes the feeling of respect one experiences upon witnessing the moral merit expressed in another's action as "a tribute that we cannot refuse to pay to merit, whether we want to or not" (KpV 5:77). Here the topic appears to be moral appraisal-respect. But the passages we will focus on in the main text seem to us to be clearly about recognition-respect.

${ }^{9}$ English translations are from the Cambridge Edition of Kant's works. Our abbreviations for the relevant works are: 'G' for the Groundwork, 'KpV' for Critique of Practical Reason, and 'MS' for the Metaphysics of Morals.

${ }^{10}$ The second conjunct in 6 is also phenomenological, but it appears to merely recapitulate 5 . As for 1-3, 78 , and the first conjunct of 6 , these appear to concern causal antecedents rather than phenomenal constituents of respect.
} 
[9] Respect is properly the representation of a worth that infringes upon my self-love. Hence [10] there is something that is regarded as an object neither of inclination nor of fear, though it has something analogous to both. [11] The object of respect is therefore simply the law, and [12] indeed the law that we impose upon ourselves and [13] yet [regard it] as necessary in itself. [14] As a law we are subject to it without consulting self-love; [15] as imposed upon us by ourselves it is nevertheless a result of our will; and [16] in the first respect it has an analogy with fear, [17] in the second with inclination. [18] Any respect for a person is properly only respect for the law (of integrity and so forth) of which he gives us an example. [19] Because we also regard enlarging our talents as a duty, [20] we represent a person of talents also as, so to speak, an example of the law (to become like him in this by practice), and [21] this is what constitutes our respect. [22] All so-called moral interest consists simply in respect for the law. (G 4:401n; emphases original).

We may set aside remarks 18-21, which appear to concern moral appraisal-respect, and concentrate on the remaining elements, which concern recognition-respect proper. $^{11}$

As a feeling brought about not by external triggers, but by one's own intellectual apprehension of an abstract principle (see [1]-[2]), Kant's feeling of respect is suffused with a cognitive or intellectual dimension. There is a (somewhat old-fashioned) way of thinking of feelings that cast as purely sensory, often visceral, experience (James 1984). But on our (more modern!) conception of emotional feelings, they are much more complex, more textured experiences incorporating, among other things, a proprietary cognitive phenomenology, that is, the experience of engaging in conceptual thought (for this conception of emotional phenomenology, as involving cognitive phenomenology as constituent, see Kriegel 2014). It is clear that this kind of cognitive phenomenology is much more central to Kant's conception of what it is like to experience recognition-respect than anything to do with, say, visceral sensations.

If one revisits the sampling of phenomenological observations cited in the previous section, it is clear that many, if not all, are reflected in Kant's description. At the same time, Kant's formulations are more specific in phenomenological detail, thus yielding a distinctively Kantian conception of respect. One can detect, moreover, several "clusters" of salient phenomenological elements from Kant's description.

One cluster revolves around awareness of the moral law in the experience of respect:

- Recognition-respect is a particular mode of apprehending a person, in which one pays attention to and perceives her or him differently. In particular:

\footnotetext{
${ }^{11}$ Recall that appraisal respect is Darwall's label for the kind of respect which contrasts with recognitionrespect and which is grounded in appreciation of a person's individual accomplishment or attributes.
} 
- Recognition-respect involves awareness of the moral law. [4]

- Recognition-respect has as its focus the moral law and its relation to one's desires and aversions. [11]

- Recognition-respect requires trying to apprehend clearly the relation between the moral law and one's desires and aversions. [5]

- Recognition-respect is a representation of a worth that infringes on one's self-love (one's self-regarding desires and aversions). [9]

- Recognition-respect involves exercising one's agency by imposing the law on oneself. [12]

This last claim paves the way to the core phenomenal feature of recognition-respect, namely, the subordination of one's will to the moral law:

- Recognition-respect involves heeding the law without consulting self-love. [14]

- That is, recognition-respect involves actively subordinating one's desires and aversions to the moral law. [15]

- Recognition-respect is object-generated in the sense that the moral law is experienced as demanding that moral reasons be given normative priority over reasons grounded in self-regarding desires and aversions. [13]

- At the same time, recognition-respect is also an expression of agency: it is a deliberate, directed attention, rather than grabbed attention, of reflective consideration and judgment. [Implicit in 12]

In addition to the active subordinating of one's will to the moral law, Kant also highlights one's awareness of doing so:

- Recognition-respect requires apprehending a subordination relation obtaining between the moral law (and its particular requirements) and one's desires and aversions. [5]

- It thus involves apprehending the normative superiority of the moral law (including its particular requirements) compared to reasons grounded in one's desires and aversions. [Implicit in 5]

- Recognition-respect involves the recognition of the law directly determining one's will without reference to one's desires and aversions. [14]

Finally, Kant also makes two claims about phenomenal overlaps between respect and fear, on the one hand, and inclination, on the other:

- Recognition-respect, because it involves attending to the subordination of one's desires and aversions to a law whose normative force is independent of 
our will, is similar to fear insofar as it has something exogenous (willindependent) about its source. $[14,16]$

- However, because it also involves an exercise of one's will whereby one actively subordinates desires and aversions to the requirements of the moral law, recognition-respect is also similar to inclination insofar as it has something endogenous (will-based) about its sources. [15, 17]

These similarities to fear and inclination may seem quite incidental to recognitionrespect, but they appear to resurface stubbornly in Kant's descriptions of respect.

\section{Kant on the Experience of Recognition-Respect: II. The Contrastive Phenomenology of the Doctrine of Virtue}

Phenomenological Ramsey sentences offer one kind of phenomenological perspective on the experience of respect for persons. Another potentially instructive perspective may be provided by phenomenal contrasts, whereby core phenomenal features of respect are put in sharp relief by the contraposition of the experience of respect with the experience of neighboring moral experiences. ${ }^{12}$ By meticulously comparing and contrasting the experience of respect with the experience of other moral emotions - such as guilt, shame, admiration, and so on - one could inform our grasp of the phenomenal character distinctive of respect for persons.

Kant does not offer anything like this kind of comprehensive web of phenomenal contrasts. However, in Kant's final work in moral philosophy, the Metaphysics of Morals, part II, the Doctrine of Virtue, he offers focal remarks about recognition-respect for persons, often by juxtaposition with a certain (ethically fundamental) kind of love. In that work, Kant sets forth a system of mid-level duties - duties that mention act types, such as beneficence and gratitude, that are grounded in the more abstract, high-level categorical imperative, and from which one can infer concrete duties taking into account one's particular circumstance. He divides mid-level duties to others into duties of love toward others and duties of respect for others. ${ }^{13}$ Importantly, by "love" Kant does not mean anything like romantic love. Already in the Groundwork, he distinguishes between pathos-based love (pathologische Liebe) and a duty-based love, which he calls "practical love" (G 4:399). The former is a passion, something that happens to us rather than something we directly control. In consequence, it makes no sense to command such love. In contradistinction, practical love is something that can very sensibly be commanded,

\footnotetext{
${ }^{12}$ This contrast methodology is heavily used in current discussions of perceptual experience (see notably Siegel 2011), as well as so-called cognitive and conative (or agentive) phenomenology (see Kriegel 2015).

${ }^{13} \mathrm{He}$ also discusses duties to oneself, which we may set aside here.
} 
because it is not a passion but an action - something that we actively adopt. What we adopt is a principle of action toward the loved one. To that extent, practical love is an action-guiding, ethically relevant emotion in the way respect is. Yet there are several striking and instructive contrasts between the two.

First of all, the duty of love requires most fundamentally that one adopt the maxim of making the well-being of others an end to be promoted. By contrast, complying with duties of respect requires, most fundamentally, that one adopt the maxim of "limiting our self-esteem by the dignity of humanity in another person" (MS 6:449). The experience of respecting another person involves a felt exhortation not to use her merely as a means to our own ends. But it does not involve a felt exhortation to adopt her ends as our own, that is, to commit ourselves to pursuing these ends as though they were our own ends (though respect certainly appears to be compatible with such commitment - see G 4:430). By contrast, it is of the essence of the experience of practical love that the other's ends are taken on as though they were our own. This is perhaps the most fundamental difference between the two experiences.

From this fundamental difference flows another basic and quite abstract difference: the duty of respect embodies an essentially "negative" requirement, whereas the duty of love embodies a "positive" requirement. To that extent, the experience of practical love toward a person involves a felt motivation to engage in certain actions, whereas the experience of respecting a person involves a felt motivation to refrain from certain actions. The experience of practical love is that of being motivated to go ahead and do something for the furtherance of the loved one's ends, whereas the experience of respect is that of being motivated to pull back and let the respected one pursue her ends.

One suspects, however, that the contrast between recognition-respect and practical love runs deeper than the two states' relations to others' ends and affects also relations to means. For it follows from the foregoing that when a person we both love and respect chooses what we think is the instrumentally wrong means in the pursuit of her ultimate end, our love for the person and our respect for her will issue conflicting recommendations: our love for the person makes us palpably want to correct her choice of means, or otherwise to intervene to avoid the failure and disappointment we expect to attend her ill thought out choice of means. In contrast, our respect for the person makes us feel the obligation to allow her to "make her own mistakes" in pursuing her life autonomously, despite the failure and disappointment we predict for her. The point is well articulated by Connie Rosati in her discussion of a related point by Darwall (2002: 14-16): 
[We] must leave room for at least two attitudes that we may take toward a person. One attitude we may take is concern, treating her as a being with a welfare. A second is respect, treating her as a being with dignity - an autonomous agent. Out of respect for a person, we may honor her choices even when, out of concern for her, we would favor a different choice for her sake. (Rosati 2009: 321)

Rosati's "concern" can be thought of as a phenomenal component of practical love. It is this component that makes practical love go beyond adoption of the loved one's ends to a willingness (in some circumstances) to overrule the loved one's choice of means. In its more negative, more modest "approach," respect is unwilling to overrule the respected person's choice of means - and does not require adoption or pursuit of her ends in the first place.

\section{एक}

The feeling of modesty is in fact crucial to Kant's phenomenological portrait of respect in the Doctrine of Virtue. Recall that at the heart of Kant's Groundwork conception of recognition-respect is the idea of subordination. In a similar vein, in discussing in the Doctrine of Virtue the duties of respect toward others - including duties to refrain from arrogance, defamation, and ridicule - Kant notes that at the heart of disrespect for others is a "lack of modesty in one's claims to be respected by others" (MS 6:462). This is what Kant calls self-conceit (Eigendünkel). This suggests that the phenomenology of recognition-respect involves the experience of modesty at its core. In contrast, modesty appears to be entirely orthogonal to love, including practical love: neither modesty nor immodesty is characteristic of either love or the absence thereof.

Underlying this contrast between respect and love is another, more general but equally crucial difference between the two: respect is essentially egalitarian, whereas love is essentially discriminatory. In loving someone and committing oneself to pursuing her ends as though they were one's own, one is singling out the person, pulling her out from the crowd so to speak, and giving her personhood a special weight. In contrast, it is of the very nature of respect that recognition-respect is owed to everyone equally. One may speculate that the reason for this is that it is psychologically possible for us to negatively avoid treating everybody as means to our own ends, but not psychologically possible for us to positively take on everybody's ends.

In one striking passage, Kant presents what is perhaps the most dramatic phenomenal difference between (recognition-)respect and (practical-)love. Drawing an analogy with laws of attraction and repulsion in the natural world of physical causes, he writes: 
In speaking of laws of duty (not laws of nature) and, among these, of laws for human beings' external relations with one another, we consider ourselves in a moral (intelligible) world where, by analogy with the physical world, attraction and repulsion bind together rational beings (on Earth). The principle of mutual love admonishes them constantly to come closer to one another; that of respect they owe one another, to keep themselves at a distance from one another... (MS $6: 449$ )

This passage comes immediately after Kant has indicated that one's duties of love and respect "are basically always united by the law into one duty" (MS 6:448), which he illustrates with the example of beneficence (Wohltun) - a duty of love. He remarks that the obligation to help others in need (e.g. the poor) should always be tempered by respect for one's beneficiary, "to spare him humiliation and maintain his respect for himself" (MS 6:448-9).

What exactly to make of Kant's force analogy has been a topic of discussion in the secondary literature. ${ }^{14}$ One thing that should be pointed out is that the contrast between a drawing-nearer force and a distancing force parallels nicely the contrast, discussed above, between the felt desire to do something for the other and the felt need to pull back. In any case, whatever one makes of the force analogy, intriguing as it is, an interpretation of Kant's conception of recognition-respect should do justice to the idea that considerations of practical love and respect are in some ways distinct, "pulling" so to speak in opposite directions, yet are importantly conjoined in one's moral involvement with others. The flavor of this opposing-forces idea should be preserved in articulating Kant's (and, we would add, Kantian) phenomenology of recognition-respect. Indeed, we may think of this as a constraint on an account of respect qualifying as properly Kantian.

To summarize, we have pointed out six phenomenal contrasts between recognition-respect and practical love, as they arise from Kant's discussion in the Doctrine of Virtue. They are: (1) refraining from using the other as means to our own ends (respect) versus committing to taking on the other's ends as though they were our own (love); (2) negative felt demand to pull back (respect) versus positive felt demand to act (love); (3) a felt need to let the other pursue her ends using the means she deems suitable (respect) versus a felt desire to overrule the other's choice of means, the better to serve the pursuit of her ends (love); (4) the felt exercise of modesty (respect) versus the complete absence of either modesty or immodesty (love); (5) an egalitarian feeling of treating all persons the same (respect) versus the discriminating feeling that gives some person a special treatment (love); (6) the felt "repulsion" keeping one at a distance from the object of

\footnotetext{
${ }^{14}$ See, for example, Baron 1997, Johnson 1997 and Filippaki 2012, and Sanchez Barboa (ms).
} 
one's experience (respect) versus the felt "attraction" drawing one closer to the object of one's experience (love).

\section{Filling out the Kantian Phenomenology of Recognition-Respect}

Unfortunately, the Doctrine of Virtue does not contain a passage that neatly condenses all of Kant's main phenomenological observations about the experience of recognition-respect (the way the Groundwork footnote discussed in $\$ 2$ does). However, with a schematic characterization of Kant's phenomenal-contrast-based account of recognition-respect now before us, we may try to articulate a Ramsey sentence that captures those observations as they come across in the Doctrine of Virtue. We take up this task in the next section.

Before starting, though, it is worth keeping in mind that Kant's primary concern here is with the phenomenology of the complex experience of respect, and not just the phenomenology of acting in ways that are merely outwardly respectful, regardless of one's feeling toward the object of such outward behavior. There is a kind of "performative respect" we show someone when we are polite toward her, avoid rude or overtly inconsiderate behavior toward her, and so on. Such behaviors are nonetheless compatible with having arrogant or ridiculing private thoughts about the person. For Kant, this would still be a case of self-conceit and a failure to recognition-respect the person.

Our task in this section, then, is to develop a more determinate conception of Kantian recognition-respect that builds on Kant's own schematic characterization but may also go beyond it. To make the experience of respect vivid in our minds during the discussion, we begin with two vignettes that we take to be representative of at least some common, indeed typical, experiences of recognition-respect. Now, in an agent who has the virtue of respect, her actions will routinely express her respect for others automatically and without effort, in a way that may make the associated phenomenology relatively subtle and hard to discern. Our cases therefore involve effortful respect, respect that does not comes easy to the person doing the respecting. The point is to make more manifest the phenomenology of recognitionrespect experienced on some occasion of recognizing a duty toward others.

Case 1: Jones is a professor teaching a course in philosophy to first-year undergraduates. During one particular class session, he responds to a student's question in a curt manner, which conveys a dismissive attitude toward the question and the student. Later that day, in thinking about that class session, and, in particular, about his handling of the student's question, he feels sheepish 
and slightly ashamed of his curt, dismissive reply, which now strikes him as telegraphing a sense of intellectual superiority over the student. He realizes that his manner conveyed a lack of respect for the student - something he (mostly successfully) aims to avoid - and that on this occasion he was just too anxious about keeping to the course material and pressing ahead with his lecture. More than that, Prof. Jones is well aware that he is sometimes mildly irritated by this student, whose questions tend to be off the mark. Jones comes to think that the combination of his feeling toward this particular student and the felt pressure to get through course material is what prompted his manner of reply. As a result of these reflections, Jones vows to himself that he won't let such pressure get to him when dealing with students in future. He is now primed to put his vow into practice, having wallowed in his shame sufficiently long that he feels a strong motivation to avoid the same moral mistake in the future. In the very next session, the same student asks a question about the course material, again betraying fundamental misunderstanding. But this time Jones puts aside competing considerations and attends patiently to the question, delivering a thoughtful and cheerful reply at a proper level of sophistication for being understood by the student and the class. Moreover, he does so while genuinely inhabiting a feeling of respect for this student as a person whose possible intellectual limitations do not make him any less of a person. Overall, Jones's demeanor conveys a proper attitude of modesty in answering the student, thus deliberately overcoming any negative feelings he may have toward this student's philosophical acumen.

Case 2: Prof. Jones is, by the way, a fresh tenure-track hire of his department's, and often discusses topics of mutual interest with his senior colleague Smith. One day, over lunch, they end up discussing the wider issue of what one might want out of an academic career as a philosopher, sharing with each other that although intellectual illumination and philosophical wisdom are what they ultimately value more, the desire for professional recognition and success can often be felt more vividly. Smith then offers Jones a number of wise tips she has garnered or formulated to herself over the years - tips essentially about how to avoid the temptations of professional vanity when the latter comes at the expense of pursuing that which they both just claimed to genuinely value more. Toward the end of the lunch, however, as the discussion veers back to more mundane matters, Jones proudly and joyfully reveals to Smith that he has been approached to apply for a prestigious fellowship; the fellowship would force him to work on a topic he is not really interested in, he says, but on the other hand it involves spending a semester at a top department, where he will make contact with some of the leading figures in his area, and the salary is higher to boot. 
Smith finds odd the discrepancy between Jones' stated life goals in the conversation they just had and the unbridled enthusiasm he shows for this fellowship. She is about to dampen his excitement with a pregnant remark, but just as she is about to do so, something holds her back. She contemplates the notions that his youth may make Jones hungrier for validation than she can relate to, and that perhaps he knows best just how much prestige he must chase in order to calm down the desire for it and be able to concentrate better on what genuinely matters to him most. She even considers that, all said and done, he may ultimately have ends different from hers, and that's okay too - "people are just different," she tells herself. She warmly wishes him success in his application and congratulates him for being approached in the first place, remarking that it is a sign of a rising notoriety and that he should be proud of himself.

Reflection on these scenarios and keeping in mind the phenomenal features brought into sharper relief through the contrast with practical love, we offer a phenomenological portrait of recognition-respect for persons that highlights four main groups of observation.

A first and paramount group of phenomenological observations pertain to the central role of modesty in recognition-respect (which comes across most vividly in Case 1):

- Recognition-respect for persons (respect, hereafter) is a particular mode of apprehending another person, in which one pays attention to and perceives that person differently. In particular:

- The attention one pays to the other person is an expression of one's modesty. ${ }^{15}$

- The modesty in question has as its focus oneself and the other person.

- Respect as modesty requires trying to apprehend clearly a particular relation between oneself and the other person.

- Respect as modesty requires apprehending, more specifically, a relation of equality between oneself and the other.

This modesty is not experienced as spontaneous, let alone as groundless. Rather, it is experienced as grounded in a special intrinsic worth that the respected person possesses - what we might call, following Kant (G 4:434), dignity:

- Respect as modesty is a representation of a worth possessed by the other person as a person with dignity equal to one's own dignity.

\footnotetext{
${ }^{15}$ For defense of an account of modesty in terms of attention, see Bommarito 2013.
} 
- Respect as modesty is a worth that infringes on one's self-love and strikes down one's self-conceit.

- Respect as modesty requires recognition of the dignity of the other as directly determining one's will regardless of one's desires and aversions.

- Respect for persons is thus object-generated in the sense that representation of the dignity of the other is experienced as demanding that consideration of this dignity be given normative priority over considerations of self-love.

- At the same time, respect is also an expression of agency: it is deliberate, directed attention, rather than grabbed attention.

- Respect involves exercising one's agency in that "I keep myself within my own bounds" (MS 6:450), in the sense that I refrain from unjustly elevating myself over others by denigrating their worth. ${ }^{16}$

In addition, there is an important group of phenomenological observations pertaining to the role of respect in relating to ends and means (highlighted by Case 2):

- Respect for persons involves a keen sense of when one is dealing with another in just the way one does in part because of what one expects to obtain from the other in virtue of so dealing.

- To that extent, respecting a person involves being aware when we start seeing her, if only in part, only qua means to our own ends.

- Respect involves the feeling of overcoming the temptation to see others only in terms of what they afford oneself in one's pursuit of one's own ends.

- Respect involves a degree of emotional acceptance of others' goals and ends, even when they differ in important ways from one's own.

- Respect also involves an element of acceptance of others' chosen means.

- Respect as acceptance, like respect as modesty, is grounded in an apprehension of the other as equal to oneself at the deepest level.

- It is also grounded in full appreciation of the distinctness or otherness of the other - the fact that she harbors an internal life which is ultimately separate from one's own.

Finally, there are also two phenomenological observations worth making about an affective valence involved in the experience of respect:

- Respect, because it requires subordinating self-love and striking down selfconceit, involves a negative feeling of humility.

\footnotetext{
${ }^{16}$ Our continuation of the quoted remark is a gloss on the remainder of the sentence, which in full reads: "I keep myself within my own bounds so as not to detract anything from the worth that the other, as a human being is authorized to put upon himself."
} 
- At the same time, because it involves a representation of one's equality with others, respect typically involves also a positive, almost cathartic feeling of being in community and fellowship with other human beings.

As before, in order to capture the theoretical role of recognition-respect for persons in the theory, we may construct a Ramsey sentence that includes these observations (plus presumably additional ones) asserting the existence of an emotion that satisfies all or most of these elements.

It might be objected that our portrait of respect is much too complex and over-intellectualizing, casting respect as an incredibly sophisticated emotion few would actually be able to experience. In response, we would like to stress two points. First, and most importantly, while some of the descriptors just used deploy high-level concepts, it does not follow that a person needs to possess the relevant concepts to just experience respect. The reason is that, in general, a person need not be in a position to articulate and accurately conceptualize every experience she is capable of undergoing. Second, however, we would like to insist that recognitionrespect really is one of the most intellectual emotions in the standard human psychological repertoire, teeming with cognitive phenomenology, and is indeed much less frequently experienced than, say, guilt or joy.

\section{Outstanding Challenges and Further Research}

We have attempted to offer a phenomenological (first-personal) rather than psychological (third-personal) characterization of Kantian respect for persons, as it comes through both in the Groundwork and in the Doctrine of Virtue. Naturally, the above is just an initial sketch, almost an illustration, of what a phenomenological approach to respect would look like. We want to close with discussion of three major challenges to the project that may open fruitful avenues of research into the phenomenology of respect.

The first and most straightforward challenge is that Kant's phenomenological characterization of respect is inadequate. For instance, several scholars have argued that Kant casts respect as overly abstract and intellectual. One immediate worry is that Kant often characterizes respect as intentionally directed, in the first instance, not at persons but at the law, and to that extent gets wrong the intentional content of respect (Drummond 2006: 2). As Kant himself puts it, "every respect for a person is properly only respect for the law ... of which he gives us an example" (G 4:401n). In response, one might allow that respect for persons is intentionally directed at persons after all, but is so directed in virtue of being directed at the law (somewhat as an auditory perception can be directed at a bus in virtue of being directed at the sound of the bus's engine). Some philosophers have charged, however, that Kant's 
focus on respecting persons only in virtue of respecting their humanity, or only in virtue of their exemplifying the law, is too "cold" and impersonal. The problem is that Kant's conception of respect for persons fails to do justice to a commonsense conception, grounded in everyday, ordinary phenomenology, according to which respecting persons "takes in" the wholeness of the person as particular agents with particular aims, interests, and concerns (Noggle 1999). Robin Dillon nicely summarizes the abstractness objection when she writes that the Kantian conception of respect for persons

\begin{abstract}
s from all particularities, regarding the details of our selves as contingencies irrelevant to our intrinsic moral worth. The morally significant feature of persons on this view is something abstract and generic, not what distinguishes one individual from another but what makes us all indistinguishably equal. An individual human being is an object of respect only insofar as she is an instance of the universal type, 'being with the capacity for rationally autonomous moral agency.' It is, in the words of the categorical imperative, the 'humanity in us' that matters morally and so calls for respect. (Dillon 1992: 116)
\end{abstract}

Because Kantian respect is focused on an abstract feature that all persons share, it is claimed to be "distant," "cool," "detached," as well as being indiscriminate, as if the particular person who has the abstract property being respected could be switched out for any other particular person - and one's respect would remain exactly the same (and equally appropriate).

There are two possible approaches to this challenge. One is to try to show that Kant's conception of respect is much less abstract and impersonal than scholars have claimed (see Bagnoli 2003). The other is to concede the generic and indiscriminate character of Kantian respect but defend it as a fitting reflection of nature of recognition-respect. We are tempted by this latter approach. In fact, we suspect that authors who demand a more "particularist" conception of recognitionrespect will find that the latter ends up collapsing into practical love. If one is impressed by the need to distinguish love and respect (or, more generally, one moral emotion that brings people closer and makes the agent adopt the other's ends as her own and another moral emotion that protects the separateness of people and makes the agent avoid treating others as means), then one must indeed cast respect as rather abstract and indiscriminating. This is of course just a sketch of a response. We do not pretend to have argued for it with these rudimentary remarks; merely to have pointed in the direction of response to which we are attracted.

A related challenge is that even if Kant's phenomenology of respect is broadly accurate, it cannot by itself be morally foundational, requiring instead supplementation by more "pathos-based" moral emotions, such as love, empathy, and care (see Dillon 1992, Sherman 1998). The objection may be put 
impressionistically as follows: an ethical system based entirely on a force of "repulsion" that keeps people at a distance is a somewhat grim and uninviting system. Surely care and concern for the happiness of others must play a role in a comprehensive ethical theory.

In response, we can only agree with the objector's sentiment. But we do not agree that Kant has missed this point. His very distinction between duties of respect and duties of love is indicative of his sensitivity to it. Duties of practical love include beneficence (or "good-doing" - Wholtun) and sympathetic feeling. The duty of sympathetic feeling is an "indirect" duty in the sense that fulfilling it plays a significant role in providing one with information and motivation to fulfill one's duty of beneficence. Proper sympathetic identification with another's plight puts one in touch with factors about her or his situation that are morally relevant in determining how one might be of help. Kant claims that sympathetic feeling is a natural instinct, which, when cultivated, can serve to motivate one to perform acts of beneficence that "representation of duty alone might not accomplish" (MS 6:457). So unlike duties of respect, fulfilling one's duty of beneficence toward others will typically involve sympathetic feeling. Importantly, because the duty of beneficence is an "imperfect" duty, it allows for latitude in complying with it, and so the phenomenology of beneficence will typically not involve a felt demand, or at least not one of the same strength as experienced in cases of recognition-respect. Although in cases of close personal relationships duties of love and of respect tend to "fuse," it is important in Kant's scheme that the differences between them not be lost in one's theorizing. It remains that a complete understanding of Kant's moral phenomenology requires a more precisely articulated picture of the complementary roles of pathos-based moral emotions (paradigmatically: love) and pathos-free ones (paradigmatically: respect).

A different challenge to the present project is that the phenomenal character of conscious experiences of respect is a morally insignificant aspect of respect. In one version, the objection may be that feeling respect toward a person is a highly energy-consuming thing, requiring as it does apprehending the person in the right way and framing one's relation to her in a very specific way. We could certainly not be expected to enter this emotionally taxing state every time we crossed a person on the street. If so, moral life cannot be governed by this kind of emotion. Some other way of negotiating our social life morally would have to be devised.

Our tentative response has two parts. On the one hand, we would like to concede the point about the emotional cost of constant jolting into a state of experienced respect. What should morally govern our interactions with others, on our view, is, ideally, a trained-in virtue of respect (or "respectfulness"). This virtue of 
respect is best thought of as a cluster of automatized, unconscious dispositions, and to that extent calls for a psychological, third-person, functional-role-based characterization rather than our phenomenological, first-person, phenomenalcharacter-based one. At the same time, we insist that while some of the manifestations constitutive of the relevant disposition are behavioral, others are experiential, and are just as constitutive. A person who consistently acted toward other persons in all the ways required by recognition-respect, but whose internal experience as she did so conformed to none of the phenomenological observations cited above, could hardly be properly described as having the virtue of respect. (Thus, a respectful zombie would appear to be inconceivable!) To that extent, a complete functional characterization of the virtue of respect presupposes a phenomenological characterization of the experience of respect. It remains, however, that a fuller account of the respective roles of respect-as-experience and respect-as-virtue in a Kantian ethics would be required for a defense of the significance of a phenomenology of respect for our grasp on moral action.

\section{References}

- Bagnoli, C. 2003. "Respect and Loving Attention.” Canadian Journal of Philosophy 33: 483516.

- Baron, M.W. 1997. "Love and Respect in the Doctrine of Virtue." Southern Journal of Philosophy (supplement) 36: 29-44.

- Bommarito, N. 2013. “Modesty as a Virtue of Attention.” Philosophical Review 122: 93-117.

- Chalmers, D.J. 1996. The Conscious Mind. Oxford and New York: Oxford University Press.

- Darwall, S.L. 1977. “Two Kinds of Respect.” Ethics 88: 36-49.

- Darwall, S.L. 2002. Welfare and Rational Care. Princeton: Princeton University Press.

- Darwall, S.L. 2008. "Kant on Respect, Dignity, and the Duty of Respect." In M. Beltzer (ed.), Kant's Ethics of Virtue. Berlin: De Gruyter.

- Dillon, R.S. 1992. "Respect and Care: Toward Moral Integration." Canadian Journal of Philosophy 22: 105-132.

- Dillon, R.S. 2018. "Respect.” The Stanford Encyclopedia of Philosophy (Spring 2018 Edition), Edward N. Zalta (ed.), URL <https://plato.stanford.edu/archives/spr2018/entries/respect/>.

- Drummond, J.J. 2006. “Respect as a Moral Emotion: A Phenomenological Approach." Husserl Studies 22: 1-27.

- Filippaki, E. 2012. "Kant on Love, Respect and Friendship." Kant Yearbook 4: 23-48.

- Gill, M.B. 2008. "Variability and Moral Phenomenology." Phenomenology and the Cognitive Sciences 7: 99-113.

- Harman, G. 1987. "(Non-Solipsistic) Conceptual Role Semantics.” In E. Lepore (ed.), New Directions in Semantics. London: Academic Press. 
- Hilbert, D. .1900. "Über den Zahlbegriff." Jahrbericht der deutschen Mathematiker-Vereinigung 8: $180-183$.

- Horgan, T. and J. Tienson 2002. "The Intentionality of Phenomenology and the Phenomenology of Intentionality." In D. J. Chalmers (ed.), Philosophy of Mind: Classical and Contemporary Readings. Oxford and New York: Oxford UP.

- Horgan, T. and M. Timmons 2005. "Moral Phenomenology and Moral Theory." Philosophical Issues 15: 56-77.

- Horgan, T. and M. Timmons 2008. "Prolegomena to a Future Phenomenology of Morals." Phenomenology and the Cognitive Sciences 7: 115-131.

- Johnson, R. 1997. "Love in Vain." Southern Journal of Philosophy (supplement) 36: 45-50.

- Kant, I. 1785/1997a. Groundwork of the Metaphysics of Morals. Trans. M. Gregor. Cambridge: Cambridge University Press.

- Kant, I. 1788/1997b. Critique of Practical Reason. Trans. M. Gregor. Cambridge: Cambridge University Press.

- Kant, I. 1797/1996. The Metaphysics of Morals. Trans. M. Gregor. Cambridge: Cambridge University Press.

- Kriegel, U. 2008. "Moral Phenomenology: Foundational Issues." Phenomenology and the Cognitive Sciences 7: 1-19.

- Kriegel, U. 2010. "Intentionality and Normativity." Philosophical Issues 20 (2010): 185-208.

- Kriegel, U. 2014. "Towards a New Feeling Theory of Emotion." European Journal of Philosophy 22: 420-442.

- Kriegel, U. 2015. The Varieties of Consciousness. Oxford and New York: Oxford University Press.

- Lewis, D..K. .1966. "An Argument for the Identity Theory." Journal of Philosophy 63: 17-25.

- Lewis, D.K. 1972. "Psychophysical and Theoretical Identifications," Australasian Journal of Philosophy 50: 249-58.

- Loar, B. 2003. "Phenomenal Intentionality as the Basis for Mental Content." In M. Hahn and B. Ramberg (eds.), Reflections and Replies: Essays on the Philosophy of Tyler Burge. Cambridge MA: MIT Press.

- Noggle, R. 1999. "Kantian Respect and Particular Persons." Canadian Journal of Philosophy 29: 449-478.

- Rawls, J. 2000. Lectures on the History of Moral Philosophy. Barbara Herman (ed.). Cambridge, MA: Harvard University Press.

- Rosati, C. 2009. "Self-Interest and Self-Sacrifice." Proceedings of the Aristotelian Society 109: 311-325.

- Sanchez Barboa, S. ms. "Kant and the Balance of Moral Forces."

- Sherman, N. 1998. "Concrete Kantian Respect." Social Philosophy \& Policy 15: 119-148.

- Siegel, S. 2011. The Contents of Visual Experience. Oxford and New York: Oxford University Press.

- Sinnott-Armstrong, W. 2008. "Is Moral Phenomenology Unified?" Phenomenology and the Cognitive Sciences 7: 85-97. 